\title{
Qualitative assessment of the composition of the traffic flow
}

\author{
Anastasia Shevtsova ${ }^{1 *}$, Alina Burlutskaya ${ }^{1}$ \\ ${ }^{1}$ Belgorod State Technological University named after V.G. Shukhov, Belgorod, Russia
}

\begin{abstract}
The car park is growing at a rapid pace every year. According to the official statistics of the traffic police service, on the roads of the Russian Federation, mainly passenger vehicles prevail, accounting for $80-90 \%$ of the total number of cars. Passenger vehicles include a large number of various vehicles that differ from each other in design and technical parameters, with an overall length of $2.5 \mathrm{~m}$ to $5.8 \mathrm{~m}$. The difference in overall length affects the value of the dynamic dimension and, accordingly, the throughput of the road network, which requires constant monitoring and improvement, especially when using technical traffic control systems. It is necessary to consider the influence of the main parameters of the traffic flow when calculating the saturation flow at an intersection controlled by a traffic light object.
\end{abstract}

\section{Introduction}

Changes in the regulation of technical means of traffic management make it possible to analyze the problems of calculating cycles, phases and cycles of regulation at different rates of intensity and traffic conditions. The issues of calculating the parameters of traffic light regulation were dealt with by: A.Yu. Kremenets, E.M. Lobanov, A.A. Polyakov and others abroad: F.V. Webster, T.M. Metson, A.D. Miller, who presented their methods for calculating the saturation flux $[1,2]$. Analysis of the factors that affect the calculation of traffic capacity and saturation flows at controlled intersections lead to a number of inconsistencies in traffic calculations, especially for turning directions. Thus, in order to determine the control cycle, taking into account the directions of movement in the node, it is necessary to correctly determine the saturation fluxes in the directions.

In the Russian Federation, the traffic light cycle is calculated in accordance with ODM 218.6.003-2011 [3]. This calculation formula takes into account only one parameter such as the turning radius. Due to the change in the main technical characteristics of cars and the geometric parameters of intersections, it is necessary to carry out additional studies to calculate the saturation flux and consider the parameters that were not taken into account earlier.

* Corresponding author: shevcova-anastasiya@mail.ru 


\section{Materials and methods}

As an object of research, we will consider the regulated intersection of one of the most active sections of the road network of the city of Belgorod (Fig. 1). At this intersection, within the framework of the study, it is necessary to conduct a qualitative assessment of the traffic flow, since when developing plans for the coordination of traffic light regulation, such parameters as: composition of traffic flow, traffic delays, traffic speed, maximum queue length are taken into account.

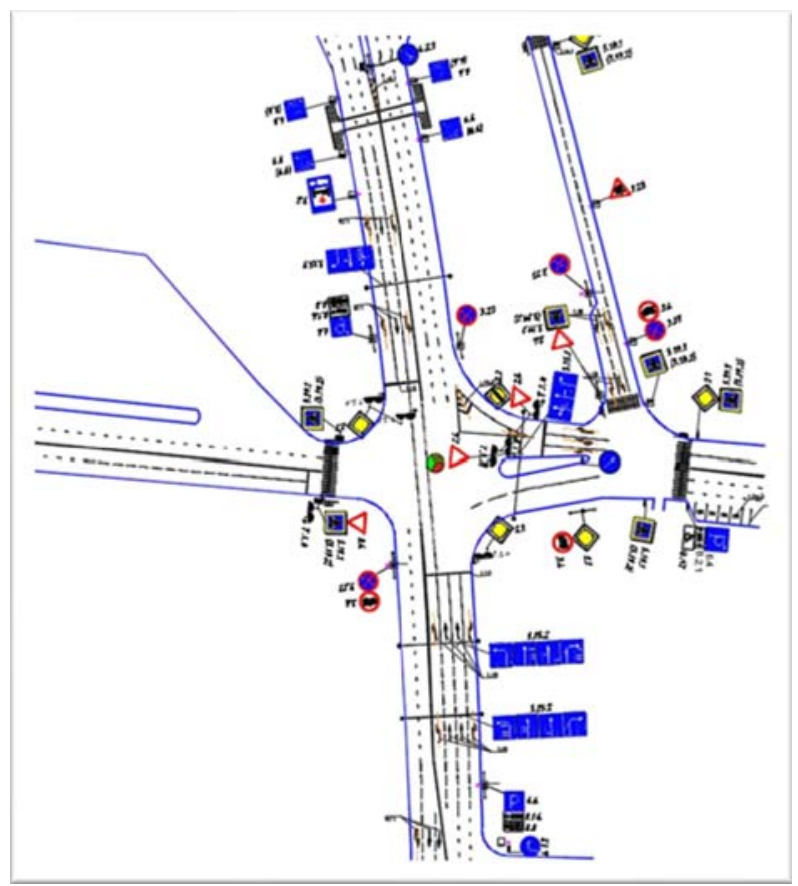

Fig. 1. The geometric scheme of the intersection of B. Khmelnitsky Ave. - Belgorodsky Ave., Belgorod.

When assessing the composition of the traffic flow in the classical way, it is customary to divide it into passenger vehicles, buses and trucks. In most cities, freight transport is prohibited from moving not only in the central part of the city, but it is also prohibited to enter the city itself. Therefore, the main traffic in the city mainly consists of light vehicles and passenger vehicles - buses. Light vehicles are very diverse and all differ in their overall dimensions, power and speed characteristics. After analyzing the traffic at the intersection under study, detailed data on the composition of the traffic flow were obtained. The traffic is mainly dominated by light vehicles (85\%), buses (15\%) [4].

When examining the intensity of the traffic flow at the regulated intersection, the statistics of car sales in the Belgorod region for 2020 were taken into account. The most sold vehicles in the region are, for example, such models as: Lada Kalina; Hyundai Solaris; KIA Rio, Toyota Corolla, Renault Logan; Volkswagen Polo and others. Let us determine the technical characteristics of the most common vehicles at the intersection in order to identify a vehicle with averaged parameters [5].

Since the technical characteristics of passenger cars affect the saturation flux, due to their changes, it is necessary to carry out additional research on the calculation of the saturation flux and consider the parameters that were not taken into account earlier. In order to clarify the classification parameters of vehicles, it is proposed to introduce such a concept as a 
calibrated car, this is a conventional car, the technical characteristics of which are determined on the basis of an analysis of the most common passenger cars in the traffic flow, which includes the averaged parameters of most passenger vehicles in the flow.

As part of the study, 15 car brands were identified that are most often found in the traffic flow during an hour on the busiest day of the week.

Table 1. Technical characteristics of vehicles often found in the stream

\begin{tabular}{|c|c|c|c|c|c|c|}
\hline $\begin{array}{c}\text { Vehicle } \\
\text { modification }\end{array}$ & $\begin{array}{c}\text { Engine } \\
\text { volume, } \\
\mathbf{c m}^{3}\end{array}$ & $\begin{array}{c}\text { Power, } \\
\text { h.p. }\end{array}$ & $\begin{array}{c}\text { Acceleration } \\
\text { time to 100 } \\
\text { km / h per } \\
\text { second. }\end{array}$ & $\begin{array}{c}\text { Length x width } \\
\mathbf{x} \text { height, mm }\end{array}$ & $\begin{array}{c}\text { Wheelbase, } \\
\text { mm }\end{array}$ & $\begin{array}{c}\text { Full } \\
\text { weight, } \\
\text { kg }\end{array}$ \\
\hline $\begin{array}{c}\text { LADA } \\
\text { PRIORA }\end{array}$ & 1596 & 106 & 11,5 & $4400 \times 1680 \times 1420$ & 2492 & 1570 \\
\hline VAZ 2112 & 1499 & 91 & 12,5 & $4170 \times 1680 \times 1420$ & 2492 & 1545 \\
\hline $\begin{array}{c}\text { Hyundai } \\
\text { Solaris }\end{array}$ & 1396 & 107 & 11,4 & $4375 \times 1700 \times 1470$ & 2570 & 1565 \\
\hline KIA Rio & 1396 & 107 & 12,3 & $4240 \times 1695 \times 1470$ & 2500 & 1560 \\
\hline $\begin{array}{c}\text { Toyota } \\
\text { Camry }\end{array}$ & 2362 & 167 & 9,1 & $4815 \times 1820 \times 1480$ & 2775 & 1520 \\
\hline $\begin{array}{c}\text { Renault } \\
\text { Logan }\end{array}$ & 1598 & 113 & 10,7 & $4346 \times 1733 \times 1517$ & 2634 & 1550 \\
\hline $\begin{array}{c}\text { Volkswagen } \\
\text { Polo }\end{array}$ & 1395 & 125 & 9,0 & $4390 \times 1699 \times 1467$ & 2553 & 1740 \\
\hline Mazda3 & 1500 & 120 & 11,9 & $4475 \times 1795 \times 1450$ & 2700 & 1775 \\
\hline $\begin{array}{c}\text { Nissan } \\
\text { Qashqai }\end{array}$ & 1598 & 115 & 12 & $4320 \times 1780 \times 1610$ & 2630 & 1830 \\
\hline $\begin{array}{c}\text { Mitsubishi } \\
\text { Lancer }\end{array}$ & 1590 & 117 & 10,8 & $4570 \times 1760 \times 1505$ & 2635 & 1750 \\
\hline Audi A6 & 1798 & 190 & 7,9 & $7933 \times 2086 \times 1461$ & 2912 & 2115 \\
\hline BMW x6 & 2993 & 381 & 5,2 & $4909 \times 1989 \times 1702$ & 2933 & 2900 \\
\hline $\begin{array}{c}\text { Chevrolet } \\
\text { Lacetti }\end{array}$ & 1399 & 95 & 11,6 & $4515 \times 1725 \times 1445$ & 2600 & 1660 \\
\hline $\begin{array}{c}\text { Daewoo } \\
\text { Matiz }\end{array}$ & 995 & 64 & 17 & $3595 \times 1595 \times 1520$ & 2375 & 770 \\
\hline
\end{tabular}

Having studied the technical characteristics of vehicles that are most often found in the traffic flow (Table 1), we see that the heterogeneity of the traffic flow increases every year, new brands of vehicles with improved modifications appear. Cars are becoming more agile and more powerful. Let's define a new calibrated vehicle with averaged data, which we can use when calculating the saturation flux (Table 2) [6].

Table 2. Technical characteristics of the calibrated vehicle

\begin{tabular}{|c|c|c|c|c|c|}
\hline $\begin{array}{c}\text { Vehicle } \\
\text { modification }\end{array}$ & $\begin{array}{c}\text { Engine } \\
\text { volume, } \\
\mathbf{c m}^{\mathbf{3}}\end{array}$ & Power, h.p. & $\begin{array}{c}\text { Acceleration time } \\
\text { to } \mathbf{1 0 0} \mathbf{~ k m} / \mathbf{h} \text { per } \\
\text { second. }\end{array}$ & $\begin{array}{c}\text { Length } \mathbf{x} \\
\text { width } \mathbf{x} \\
\text { height, } \\
\text { mm }\end{array}$ & $\begin{array}{c}\text { Wheelbase, } \\
\mathbf{m m}\end{array}$ \\
\hline 1537 & 126 & 10,9 & $4653 \times 1766 \times 1472$ & 2628 & 1703 \\
\hline
\end{tabular}

\section{Experiment}

The classical formula for the saturation flux $(\mathrm{Mn})$ is the basis for the subsequent calculation and determination of the coordinated control cycle. It includes: vehicle intensity, lane width, turning radius. In any case, no matter how we define it, the throughput depends on a large number of factors [7]: 
1. road conditions (width of the carriageway, longitudinal slope, radius of curves in the plan, distance of visibility, etc.),

2.the composition of the car stream,

3.the availability of means of regulation,

4. weather and climatic conditions,

5. the ability to maneuver vehicles across the width of the carriageway,

6. psychophysiological characteristics of drivers and vehicle design.

A change in these factors results in significant fluctuations in throughput throughout the day, month, season, and year. With a frequent location of obstacles on the road, significant fluctuations in speed occur, leading to the appearance of a large number of cars moving in groups, as well as a decrease in the average speed of the entire stream.

In the classical formulas for calculating the saturation flux $(\mathrm{Mn})$, due attention is also not paid to which class of car makes a turn and at what speed. In this regard, we will display the main additions according to this formula:

1. A clear geometric definition of the turning radius when making a left-turn or right-turn maneuver.

2. Limiting the speed of the maneuver. This criterion is one of the most important, since when making a turn, the driver slows down and chooses the safest trajectory in order to reduce the possibility of leaving the oncoming lane.

3. Determination of the safety distance to the vehicle in front when performing a maneuver, taking into account its overall length $[9,10]$.

After defining the additions, it is possible to derive a formula for determining the saturation flux of turning directions using the missing values:

$$
M_{\mathrm{H} p o v}=\frac{3600 \times\left(3,6 \sqrt{R_{\mathrm{g}} \varphi_{c}}\right)}{L_{a}+\left(T \times \vartheta+\left(\frac{\vartheta^{2}}{2 j_{z}}\right)\right.},
$$

where $R_{g}$ - is the turning radius of vehicles, $m, \varphi_{c}$ - is the coefficient of adhesion, $L_{a}$ is the overall length of an exemplary vehicle with averaged data of a certain class, $\mathrm{m}, \mathrm{T}$ - is the driver's reaction time, $\mathrm{s}, \vartheta$ - is the vehicle speed, $\mathrm{j}_{\mathrm{z}}$ - is the steady-state deceleration value, $\mathrm{m} / \mathrm{sec}^{2}$.

Having determined the formula for the saturation flux taking into account the new parameters, it becomes possible to develop an algorithm for calculating the saturation flux of coordinated motion. The data obtained made it possible to improve the algorithm for calculating the coordination plan of a traffic light object, taking into account the qualitative composition of the traffic flow (Fig. 2).

From the algorithm developed by us for calculating the saturation flow for coordinated movement (Fig. 2), it can be seen that to calculate the control cycle, it is necessary to take into account the developed formula for the saturation flux, which takes into account such parameters as: the radius of the turning direction, the critical speed of movement of vehicles, the state of the asphalt concrete pavement taking into account the weather and climatic conditions (dry, wet) and the characteristics of the calibrated vehicle, namely its overall length. Having calculated the saturation flow according to the developed formula, it is possible to calculate the phase coefficients, main and intermediate cycles, based on the results of which we determine the optimal control cycle at the intersection. 


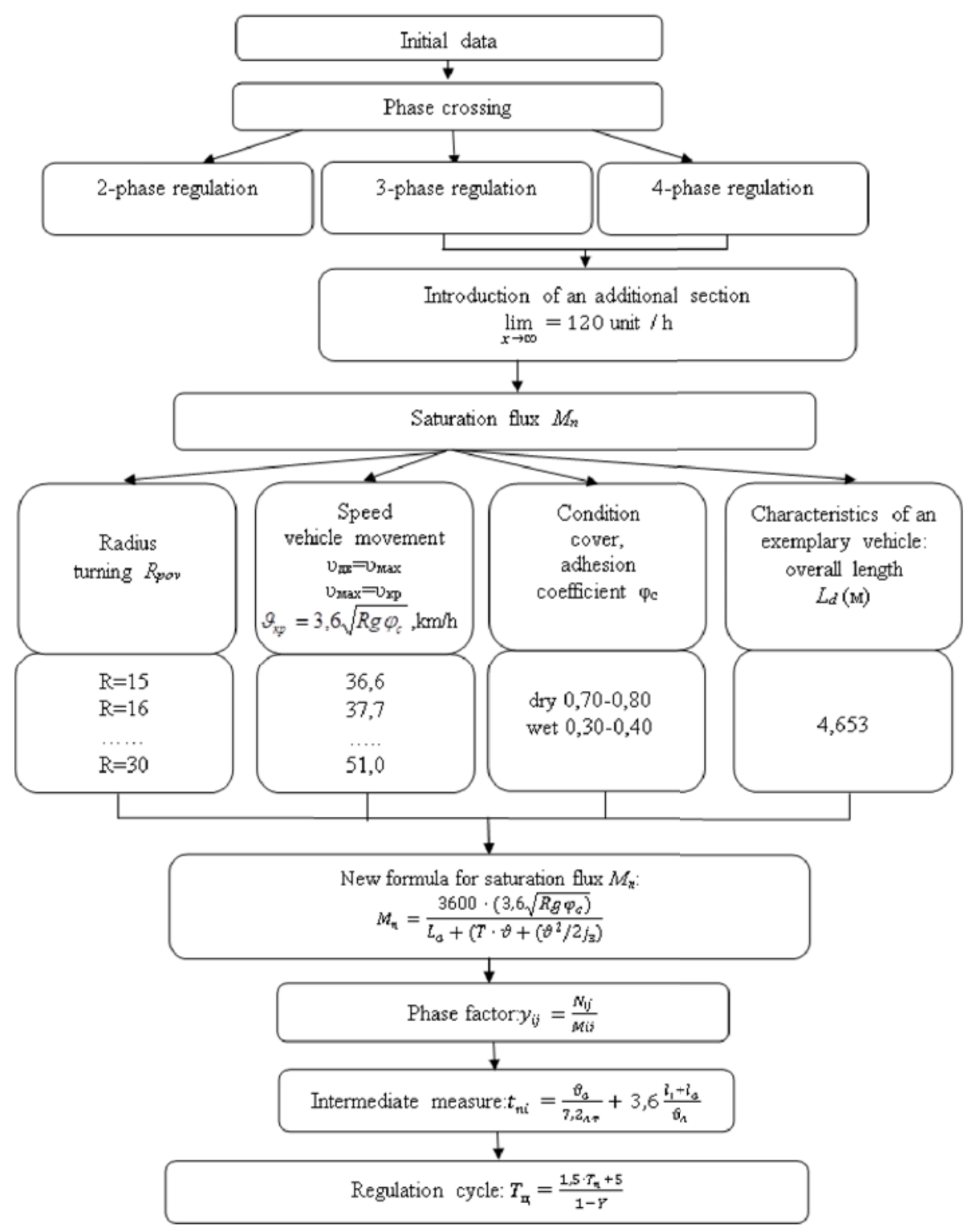

Fig. 2. Algorithm for calculating saturation flux for coordinated movement

\section{Conclusion}

Based on the scientific and analytical research, we came to the following conclusion: the composition of the traffic flow has a significant impact on the establishment of traffic light control modes. It is necessary to carry out a qualitative assessment of the composition of the traffic flow, since for a more accurate calculation of the saturation flow, additional parameters must be taken into account, such as the overall parameters of vehicles, weather and climatic conditions, geometric characteristics of the intersection.

Every year, the heterogeneity of the traffic flow is increasing, brands of vehicles with improved modifications (maneuverability, power, dimensions) appear, so it is necessary to 
take into account the overall parameters in the formula for calculating the saturation flow. In this regard, additional studies were carried out based on short-term analysis using video recording systems. Information about the main characteristics of the traffic flow was collected and the calibrated vehicle was determined.

Taking into account the new parameters, an improved formula for calculating the saturation flux was obtained, on the basis of which an algorithm was developed that allows determining the most rational cycle of traffic light regulation at intersections when organizing traffic.

\section{References}

1. V.V. Zyryanov Methods for determining the minimum required saturation level of the road network with test vehicles // Scientific Review. 2014. No. 11-3. P. 949-952.

2. A. N. Krasnikova, A. Sh. Kocharyan. Methodical recommendations for calculating the throughput of regulated intersections with different layouts and traffic organization schemes. -M.: 1987. - P. 35.

3. ODM 218.6.003-2011. Industry road methodological document. Guidelines for the design of traffic light objects on highways. M .: Federal Road Agency

(ROSAVTODOR). M .: P. 2013.

4. Burlutskaya A.G., Shevtsova A.G. Formation of an approach to the qualitative assessment of the composition of the traffic flow in the development of plans for the coordination of traffic light regulation // Information technologies and innovations in transport. Materials of the VI International Scientific and Practical Conference. Under the general editorship of A.N. Novikov. 2020. - P. 29-32.

5. Technical characteristics of cars [Electronic resource]. Access mode http://www.autowe.ru/, free

6. Novikov I.A., Shevtsova A.G., Kravchenko A.A., Burlutskaya A.G. Development of a methodology for adapting the model of controlled intersection // Bulletin of the Siberian State Automobile and Road University. 2020.Vol. 17. No. 6 (76). P. 726-735.

7. Silyanov V.V. The theory of traffic flows in road design and traffic management. - M.: Transport, 1977.- P. 303.

8. Burlutskaya A.G., Shevtsova A.G., Eronin A.D., Jung A.A. Influence of parameters on the introduction of an additional left-turn section when using traffic light regulation // In the collection: Logistic audit of transport and supply chains. materials of the III international scientific and practical conference. Tyumen, 2020. P. 30-35.

9. Borovskoi A.E., Shevtsova A.G. Methods for determining the saturation flow of a highway // World of Transport. 2013. T. 11.No. 3 (47). P. 44-51.

10. Shevtsova A.G. Improvement of the organization of traffic on the basis of rational management of a traffic light object: dis. Cand. those. Sciences: 05.22.10 / Shevtsova Anastasiya Gennadevna; Orel, 2015 - P. 92. 